\title{
ROLE OF THE INTERNET IN STRENGTHENING SOCIAL CAPITAL IN EU RURAL AREAS
}

\begin{abstract}
Magdalena KOZERA-KOWALSKA, Faculty of Economics and Social Sciences, Department of Law and Enterprises Organisation in Agribusiness, Poznan University of Life Sciences, Dojazd 11, 60-637 Poznań, Poland, kozera@ up.poznan.pl (coresponding author) Adam KOZIOLEK, Polish Agricultural Publishing Company, Poland
\end{abstract}

The article discusses the role of the Internet as an innovative form of interpersonal communication. We assumed that Internet usage in rural areas may not only result in better access to knowledge and information, but also contribute to stronger social cohesion and prevent exclusion of the elderly. We analysed information about individual Internet users in Poland and the EU, including changes related to age, education and domicile. The data enabled us to identify expected change tendencies in rural areas. We highlighted the process of ageing of European farmers with its related social and economic consequences. Against this background, we show the dual role played by the Internet in strengthening social capital in rural areas. On the one hand, it is educational in that it educates and activates young farmers. On the other, it is social, i.e. it helps the elderly stay in touch and participate in social life. We also raised the problem of potential digital exclusion of the elderly.

Keyword: digital exclusion of the elderly, Internet, social capital, rural areas

\section{INTRODUCTION}

When reading publications devoted to social capital, we may find reflections on both its resurgence and its decline. This is equally valid for rural and urban areas. On the one hand, researchers recognise the need to rebuild social bonds and trust, and on the other they describe the conformist behaviour of individuals who are indifferent to others (Skrzypiec, 2008; Halamska, 2009; Działek, 2011; Betancourt, Clague, 2008; Fedyszak-Radziejowska, 2011). We cannot state categorically which of these perspectives is correct. We should rather conclude that they are concurrent, coming to the fore or receding into the background depending on circumstances and social needs. This paper has a contribution character and take under consideration problems of rural areas social capital rebuilding. This is also placing in discussion about significance of migration from these areas to cities and conversely. As aim of this article is taken analyse of possibilities to use Internet as an innovative form of interpersonal contacts, which can cause the rebuild of social capital, especially in groups of people vulnerable to economic, digital and social exclusion.

\section{MATERIALS AND METHODOLOGY}

The article uses the information we gathered during literature studies, reviewing the publications devoted to the subject. We attached particular importance to studies into the impact of the Internet on social capital, assuming that it is a medium with a lot of potential to influence communities living in rural areas. Research conclusions are presented synthetically, including by means of graphs, to pave the way for analysing the data obtained from EUROSTAT and GUS. The statistics illustrating the assumptions behind the paper relate, among others, to the number and structure of agricultural holdings in the EU, the age of their owners and the selected attributes describing the use of electronic media and the Internet in Poland. The data was analysed with statistical methods and presented in the form of graphs and tables.

\section{RESULTS AND DISCUSSIONS}

\section{Social capital vs. social media}

Social capital is most often defined as contacts and interpersonal networks among people who are members of a given community. Relating to all areas of social life, such contacts and networks are usually horizontal. The basic feature of this kind of capital is that it integrates individuals around specific ideas with a tangible impact on the living conditions of the community.

From the point of view of the economy, social capital has long been recognised as a realistic method of achieving welfare in the lives of individuals, communities and countries (Fukuyama, 1997). However, the application of this method 
requires conscious, multilevel interventions both from the state as well as local governments (Czapiński, 2008). In practice, social capital is perceived as the domain of individuals unified around a common idea related to the community to which they belong. In today's social and economic reality, this approach is sometimes insufficient to achieve common goals. An alternative solution is to adopt a broader understanding of social capital as a kind of private-public asset (Putman, 2008). Such an approach strengthens the actions of individuals and their engagement in public affairs, brining to light the benefits of being a member of the community and participating in its resources.

Because social capital is difficult to measure, it is described qualitatively by referring to its individual properties. The properties are very varied, including knowledge, striving towards change, key skills, aspirations of social groups, social trust, common values, self-identification with a social group or region and cooperation. They are held together by interpersonal communication in which diverse means are used to reach information receivers who are members of a given community. This concept refers to the perception of social capital in its fundamental aspect, i.e. as a network of relationships and acquaintances based on friendship, mutual trust, professional understanding and an awareness of shared interests (Kostera, 2008). All of this is raised to a totally new dimension today with the development of ICT technologies which make it possible to set up communities of knowledge and experience, while their users experience a form of embedding in the community. The technologies also contribute to the emergence of unofficial communication platforms in local communities which, being almost completely cost-free and asynchronous, are often a springboard for social endeavour to the benefit of the immediate environment (Wronka, Saryjusz-Wolska 2013).

The internet is the basic form of contemporary communication whose role in building social capital has not been fully identified. Besides its obvious benefits, it is also described from the perspective of its drawbacks (Fig. 1).

Negative $\quad$ Positive

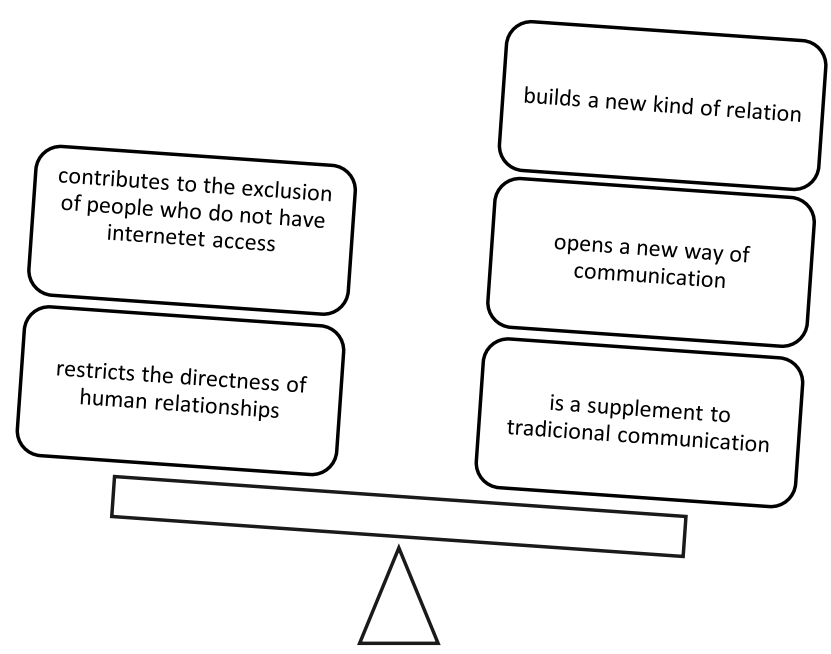

Source: own study

Fig. 1 Balance of Internet's impact on social capital

Deeply rooted in local realities, network forms of Internet communication are based, for example, on interactive learning (e-learning) as well as creating (or searching), disseminating and marketing of innovations. But they also pose a threat of excluding those members of the community whose cultural and technological competences are poor, which may prove particularly negative in rural areas (Czapiński, Panek, 2009). Modern networking is also accused of making relationships between community members less direct, moving them to the virtual domain. Given such differences in opinion, the role of the Internet and its influence on social capital is still the object of debates which also involve the term "virtual social capital". The Internet is denounced as a medium building superficial social bonds at the cost of direct contacts. Hence, it should be considered as a tool for businesslike achievement of tasks rather than genuine social capital understood traditionally (Batorski, 2005), which does not belittle the contribution of web-triggered actions to the life of a given community.

\section{Internet as a medium contributing to the development of social capital in Polish rural areas}

Today, without the presence of the media, especially electronic media, the flow of information between different social groups would be very difficult and even impossible in many cases (Batko, Kostera, 2015). Still, the level of access to such media leaves much to be desired, particularly in rural areas. When citing the data illustrating this phenomenon in Poland, however, we need to bear in mind that access to the Internet through computers and mobile devices is now much better compared to some years ago, i.e. at the moment when Poland joined the EU. Over the last years, Poland has gone 
through the process of bridging the digital gap. At the same time, the use of the Internet has diversified hugely when it comes to the sex, age, education or domicile of users (Tab. 1). By analogy, this tendency may be considered true for the growth of "networking" in many other EU Member States developing under similar circumstances.

Tab. 1. Regular computer users in Poland (in \% of total individuals in a group)

\begin{tabular}{|c|c|c|c|c|c|c|c|c|c|c|c|c|c|}
\hline \multirow{2}{*}{ Specification } & \multicolumn{13}{|c|}{ Years } \\
\hline & 2004 & 2005 & 2006 & 2007 & 2008 & 2009 & 2010 & $2011 *$ & 2012 & 2013 & 2014 & 2015 & 2016 \\
\hline Total & 35 & 40 & 43 & 46 & 50 & 55 & 58 & 59 & 60 & 61 & 64 & 65 & 69 \\
\hline \multicolumn{14}{|c|}{ Sex } \\
\hline Women & 36 & 41 & 45 & 48 & 51 & 57 & 59 & 60 & 61 & 62 & 64 & 66 & 70 \\
\hline Men & 33 & 39 & 41 & 45 & 49 & 53 & 56 & 58 & 59 & 60 & 63 & 64 & 69 \\
\hline \multicolumn{14}{|c|}{ Age } \\
\hline 16-24 years & 70 & 79 & 83 & 87 & 90 & 94 & 95 & 95 & 95 & 96 & 95 & 97 & 96 \\
\hline $25-34$ & 45 & 52 & 60 & 66 & 73 & 81 & 84 & 86 & 88 & 90 & 90 & 90 & 90 \\
\hline $35-44$ & 33 & 42 & 47 & 52 & 55 & 64 & 69 & 72 & 76 & 77 & 78 & 79 & 83 \\
\hline $45-54$ & 25 & 29 & 31 & 34 & 39 & 45 & 49 & 50 & 51 & 53 & 58 & 62 & 63 \\
\hline $56-64$ & 13 & 16 & 16 & 18 & 23 & 26 & 27 & 30 & 32 & 33 & 39 & 42 & 46 \\
\hline $65-74$ years & 3 & 3 & 3 & 4 & 6 & 7 & 9 & 12 & 15 & 17 & 20 & 20 & 24 \\
\hline \multicolumn{14}{|c|}{ Educational level } \\
\hline $\begin{array}{l}\text { Primary school } \\
\text { or lower-secondary school }\end{array}$ & 31 & 34 & 34 & 36 & 35 & 39 & 42 & 40 & 39 & 40 & 44 & 42 & 52 \\
\hline Secondary school & 30 & 35 & 38 & 42 & 46 & 51 & 53 & 54 & 56 & 55 & 58 & 58 & 63 \\
\hline $\begin{array}{l}\text { Higher Educational } \\
\text { Institution }\end{array}$ & 72 & 77 & 80 & 82 & 86 & 88 & 89 & 91 & 93 & 93 & 94 & 96 & 97 \\
\hline \multicolumn{14}{|c|}{ Domicile } \\
\hline Large cities & 47 & 53 & 55 & 58 & 60 & 65 & 68 & 70 & 73 & 71 & 74 & 76 & 79 \\
\hline Towns & 38 & 41 & 45 & 48 & 54 & 58 & 60 & 60 & 60 & 62 & 65 & 65 & 71 \\
\hline Rural areas & 21 & 29 & 31 & 35 & 38 & 44 & 47 & 49 & 50 & 51 & 55 & 56 & 61 \\
\hline
\end{tabular}

*own estir

Source: Społeczeństwo informacyjne w Polsce. Wyniki badań statystycznych z lat 2004-2007, 2006-2010 oraz $2012-2016$ (IT Society in Poland. Statistical Study Results for 2004-2007, 2006-2010 and 2012-2016)

Over recent years, differences in Internet skills between men and women have been gradually disappearing. Changes have also taken place in user age structure, most dynamically in the case of the youngest people almost $96 \%$ of whom already have active access to the web. People in the 24-34, 35-44, and 45-54 age groups are trying to catch up in this area. The tendency bodes especially well for the economy as the people in these age groups are the core of the economically active population, contributing to the country's growth. Also, we cannot underestimate the changes in Internet access of other age groups. People in the pre-retirement age and seniors are much more active on-line. This is a very positive phenomenon given its potential to boost communication supporting social capital. The very fact of using the Internet is also related to the users' educational level. The present-day education system contributes to popularising the Internet among the people in the youngest age groups and those who are interested in continuing their education later in life (LLL).

It is worth mentioning that, compared to other EU Member States, the number of Internet users in Poland still leaves much to be desired, the digital gap being estimated at about $10 \mathrm{pp}$. in 2016 . The group of countries with the largest number of Internet users is led by Luxembourg (93\%) followed by Denmark (89\%) the UK (88\%), the Netherlands (86\%) and Sweden (and Finland 85\%). With Internet access at $70 \%$ of the population, Poland is in the group of countries with the lowest Internet use levels together with Greece (57\%), Bulgaria (49\%) and Romania (42\%) (Internet access and use statistics - households and individuals, 2016). Conversely, changes taking place in user groups based on age and education must be considered equivalent to the ones observed across the EU.

Analysed data suggests, however, that it is the domicile that has the strongest impact on Internet use diversity. As the years pass, rural areas are still the ones which develop relatively slowly. All the same, in spite of delays in improving Internet access after Poland joined the EU, Polish rural communities initiated many new actions using on-line communication tools. For example, cooperation was established with experts, activists, voluntary workers and people interested in rural problems who came from urban areas. This is just one potential application of ICT technologies to support the development of rural areas.

\section{Social potential of EU agriculture and the possibility to support it by IT technologies}

Development of the social potential in rural areas, especially in the context of EU agriculture, is more that a subject of isolated research reflections. For years, it has been a major problem bearing upon the achievement of the goals of the entire agricultural policy. The problem is linked to the generational shift in rural areas. It is beyond any doubt that EU farmers are getting older and the tendency is irreversible. Agriculture is drained of young people who are glad to be absorbed by other sectors offering better pay and less strenuous work. But there is also another reason behind the ageing of the farmer population - with less young people entering the sector, old farmers continue their professional activity after retirement which is not possible in other sectors of the economy (Fig. 2). 


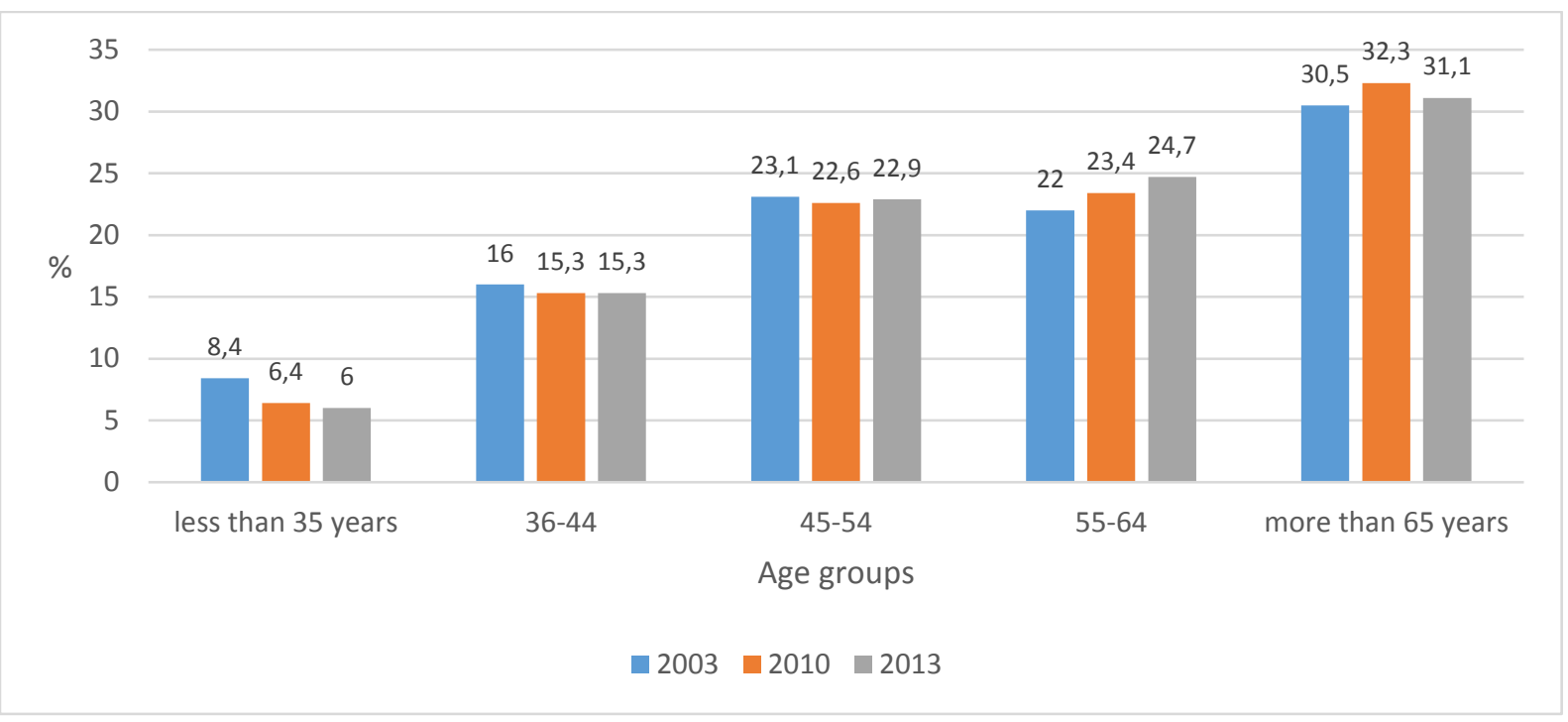

Source: calculation based on: EU farms and farmers in 2013: an update. EU Agricultural and Farm Economics Briefs No. 9. 2015

Fig. 2. Changes in the share of agricultural holdings according to owner age in UE-27 countries (in \%)

Most EU farmers are above 55 years of age, with only 6\% from the "below 35 years of age" group. Almost $30 \%$ of farmers have practically reached their retirement age $(65+)$. The calculated ratio of young farmers (below 35 years of age) to old farmers (above 55 years of age) stood at 0.11 in 2013, which means that there were 9 old farmers for each young farmer (EU farms and farmers in 2013). Nonetheless, we must put this phenomenon in the context of ongoing changes in agrarian structure, especially when it comes to farm size. On the one hand, the average size of an EU holding increased; on the other, the tendency was also more visible in farms run by the youngest group of farmers (Fig. 3). They usually own larger and more prosperous farms compared to middle-aged and old farmers. It is even mentioned that there is a link between a farmer's age and the size of his holding. According to this correlation, old farmers usually have smaller holdings. For a lot of them, running a holding is primarily a means of supplementing their pension or pursuing a hobby.

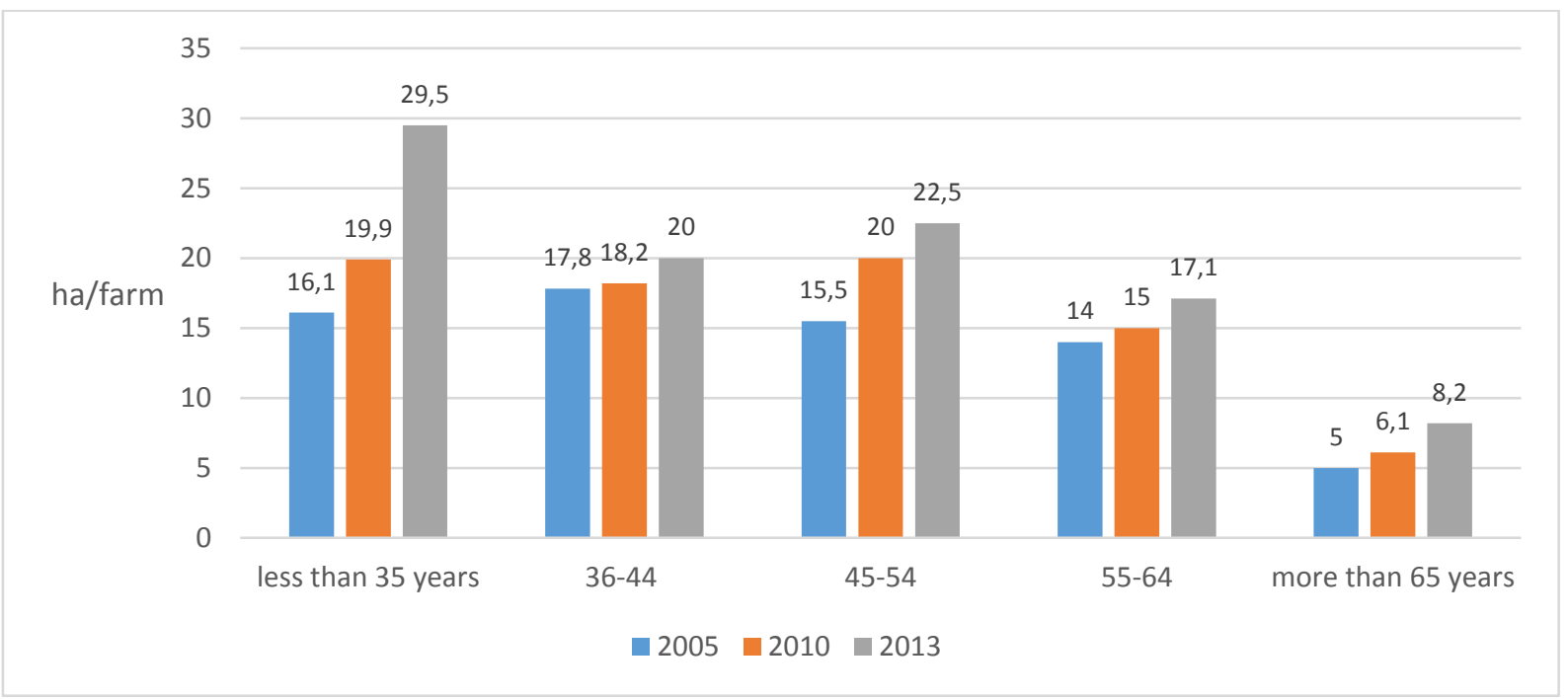

Source: based on: EU farms and farmers in 2013: an update. EU Agricultural and Farm Economics Briefs No. 9.2015

Fig. 3. Average size of agricultural holdings in UE-27 by user age group

Rural areas are usually assessed through the prism of agricultural and environmental activities (Heilig, 2003). The analysis of changes in the structure of agricultural holdings and the age of their owners demonstrates that they must also be perceived from the perspective of social changes, especially in the context of ageing farmer populations nearly everywhere in the EU. How farms will be managed in the future will be decided by young people who, just like their contemporaries from Poland, are very comfortable in the virtual reality looking for solutions that are necessary and convenient for them. The quality of life of farmers who end their professional lives is a separate issue. Such farmers represent a social group in danger of both digital exclusion and inevitable alienation caused by, for example, living far from the centres of social activity. These persons should be targeted with actions increasing their on-line mobility. All the more so that the Internet is no longer only a simple information medium, but also a point of access to offices (eadministration), education (e-learning), shops (e-commerce), advertising and marketing (e-marketing) or even leisure (etourism), work (e-work), and, increasingly, healthcare (e-health). It provides an environment removing physical barriers 
to communication and association by providing old people with an opportunity to get in touch or organise themselves through websites (e-communities). It is this last aspect of Internet use in particular that determines the role played by this medium in rural areas as an innovative method of supporting social change and improving the quality of life.

\section{CONCLUSION}

The generational shift in rural areas (young people leaving to other sectors) and changes in working conditions (especially their improvement) often raise the problem of what might be referred to as erosion of social capital in rural areas in general and villages in particular. It is manifested by weaker civic engagement and poorer sense of belonging. Technological advancement brings new solutions which galvanise the social capital in individuals in a more or less durable way, encouraging them to act for the benefit of the community. The Internet is one such solution. Besides providing knowledge and information, it also works as a communicator between separated individuals.

To participate in the virtual network of social capital, however, one needs access to the web. As it is illustrated by the example of Poland, Internet access is uneven - it is better in cities and poorer in rural areas. In addition, it varies according to the sex and age of users. Given the fact that young people are more active on the Internet, the process of ageing of populations living in EU's rural areas, especially farmers, is a worrying tendency. Rural areas lose young people running agricultural farms, that is the very people who manage their virtual contacts with great ease, using them not only for production purposes but also those activities which have been traditionally linked to social capital. On the one hand, this demonstrates the need to provide additional training on Internet use to farm owners over 35 years of age. On the other, it means that, in spite of many concerns about the negative role of the Internet in building social capital, it has become an innovative medium improving communication and, by the same token, supporting the capital of social bonds.

\section{REFERENSES}

1. Batko, R., Kostera, M. 2015. Role of the Media in Building Symbolic Capital: Example of the Public Sector in Poland. Zarzadzanie mediami, Vol. 3, No. 1, pp. 21-43. [In Polish]

2. Batorski, D. 2005. Internet and Social Inequality. Studia sociologiczne, No. 2(177), pp. 107-131. [In Polish]

3. Betancourt, Roger R., Christopher, K., Clague. 2008. Capital utilization: A theoretical and empirical analysis, Cambridge University Press, Cambridge.

4. Czapiński, J., Panek, T. 2009. Social Diagnosis. Living Conditions and the Quality of Life in Poland, Rada Monitoringu Spolecznego, Warszawa. [In Polish]

5. Czapiński, J. 2008. Human Capital and Social Capital in the Context of Material Welfare. The Polish Paradox. Zarzadzanie publiczne, No. 2(4), pp. 5-28. [In Polish]

6. Działek, J. 2011. Social Capital - Theoretical Approach and Research Practice. Studia regionalne i lokalne, Vol. 3(45), pp. 100-118. [In Polish]

7. Fedyszak-Radziejowska, B. 2011. Role of Small Agricultural Holdings in Building Social Capital in Rural Areas. Wies i rolnictwo Vol. 3, No 152, pp. 139-156. [In Polish]

8. Fukuyama, F. 1997. Trust. Social Capital and the Road to Welfare, Wydawnictwo Naukowe PWN, Warszawa - Wroclaw. [In Polish]

9. Halamska, M. 2009. Own Resource of Rural Areas and External Development Programmes Illustrated by the Relationship Between Social Capital and PP Leader+. Wieś i Rolnictwo, Vol. 3, pp. 9-28. [In Polish]

10. Heilig, G., K. 2003. Information society and the countryside: can internet-based systems bring income alternatives to rural areas? Alternatives for European Rural Areas, Rural Areas and Development, No. 1, pp. 65-79.

11. Statistics- households and individuals. 2016. Available at: http://ec.europa.eu/eurostat/statisticsexplained/index.php/Internet_access_and_use_statistics__households_and_individuals (Accessed on 28/08/2017)

12. Putnam, R. 2008. Lonely Bowling. Downfall and Renaissance of Local Communities in the USA, Wydawnictwa Akademickie $\mathrm{i}$ Profesjonalne, Warszawa. [In Polish]

13. Report on the Telecommunications Market in Poland in 2015. 2016. Urzad Komunikacji Elektronicznej, Warszawa. [In Polish]

14. Skrzypiec, R. 2008. From Participatory Revolution to...? Intermediary Structures in Poland after 1989. Przestrzen socjologii Księga jubileuszowa, pp. 292-302. [In Polish]

15. Information society in Poland. Statistical results of studies 2004-2007 years. 2007. GUS, Warszawa. [In Polish]

16. Information society in Poland. Statistical results of studies 2006-2010 years. 2010. GUS, Warszawa. [In Polish]

17. Information society in Poland. Statistical results of studies 2012-2016 years. 2016. GUS, Warszawa. [In Polish]

18. Wronka, M., Saryusz-Wolska, H. 2013. Using Social Media to Build Social Capital. Studia Ekonomiczne - Uniwersytet Ekonomiczny w Katowicach, Vol. 157, pp. 47-57. [In Polish] 